\title{
Relationships between consumption of ultra-processed foods, gestational weight gain and neonatal outcomes in a sample of US pregnant women
}

\author{
Karthik W Rohatgi ${ }^{\text {Corresp., }}{ }^{1}$, Rachel A Tinius ${ }^{2}$ ， W. Todd Cade ${ }^{1}{ }^{\text {, Euridice Martinez Steele }}{ }^{3}$, Alison G Cahill ${ }^{4}$, \\ Diana C Parra ${ }^{1}$ \\ 1 Program in Physical Therapy, Washington University School of Medicine, St. Louis, Missouri, United States of America \\ 2 School of Kinesiology, Recreation, and Sport, Western Kentucky University, Bowling Green, Kentucky, United States of America \\ 3 Department of Nutrition, University of São Paulo, São Paulo, Brazil \\ 4 Department of Obstetrics and Gynecology, Washington University School of Medicine, St. Louis, Missouri, United States of America \\ Corresponding Author: Karthik W Rohatgi \\ Email address: karthik.rohatgi@wustl.edu
}

Background. An increasingly large share of diet comes from ultra-processed foods (UPFs), which are assemblages of food substances designed to create durable, convenient and palatable ready-to-eat products. There is increasing evidence that high UPF consumption is indicative of poor diet and is associated with obesity and metabolic disorders. This study sought to examine the relationship between percent of energy intake from ultra-processed foods (PEI-UPF) during pregnancy and maternal gestational weight gain, maternal lipids and glycemia, and neonatal body composition. We also compared the PEIUPF indicator against the US government's Healthy Eating Index-2010 (HEl-2010).

Methods. Data were used from a longitudinal study performed in 2013-2014 at the Women's Health Center and Obstetrics \& Gynecology Clinic in St. Louis, MO, USA. Subjects were pregnant women in the normal and obese weight ranges, as well as their newborns $(n=45)$. PEI-UPF and the Healthy Eating Index-2010 (HEl-2010) were calculated for each subject from a one-month food frequency questionnaire (FFQ). Multiple regression (ANCOVA-like) analysis was used to analyze the relationship between PEI-UPF or HEI-2010 and various clinical outcomes. The ability of these dietary indices to predict clinical outcomes was also compared with the predictive abilities of total energy intake and total fat intake.

Results. An average of $54.4 \pm 13.2 \%$ of energy intake was derived from UPFs. A 1\%-point increase in PEI-UPF was associated with a $1.33 \mathrm{~kg}$ increase in gestational weight gain $(p=0.016)$. Similarly, a $1 \%$ point increase in PEI-UPF was associated with a $0.22 \mathrm{~mm}$ increase in thigh skinfold $(p=0.045), 0.14 \mathrm{~mm}$ in subscapular skinfold $(p=0.026)$, and 0.62 percentage points of total body adiposity $(p=0.037)$ in the neonate.

Discussion. PEI-UPF (percent of energy intake from ultra-processed foods) was associated with and may be a useful predictor of increased gestational weight gain and neonatal body fat. PEI-UPF was a better predictor of all tested outcomes than either total energy or fat intake, and a better predictor of the three infant body fat measures than HEI-2010. UPF consumption should be limited during pregnancy and diet quality should be maximized in order to improve maternal and neonatal health. 
Relationships between consumption of ultra-processed foods, gestational weight gain and neonatal outcomes in a sample of US pregnant women

Karthik W. Rohatgi ${ }^{1}$, Rachel A. Tinius ${ }^{2}$, W. Todd Cade $^{1}$, Euridice Martinez Steele ${ }^{3}$, Alison G. Cahill ${ }^{4}$, Diana C. Parra ${ }^{1}$

${ }^{1}$ Program in Physical Therapy, Washington University School of Medicine, St. Louis, Missouri, United States of America

${ }^{2}$ School of Kinesiology, Recreation, and Sport, Western Kentucky University, Bowling Green, Kentucky, United States of America

${ }^{3}$ Department of Nutrition, University of São Paulo, São Paulo, Brazil

${ }^{4}$ Department of Obstetrics and Gynecology, Washington University School of Medicine, St. Louis, Missouri, United States of America

Corresponding Author:

Karthik W. Rohatgi ${ }^{1}$

Email address: karthik.rohatgi@wustl.edu 


\section{Abstract}

2 Background. An increasingly large share of diet comes from ultra-processed foods (UPFs), which are 3 assemblages of food substances designed to create durable, convenient and palatable ready-to-eat 4 products. There is increasing evidence that high UPF consumption is indicative of poor diet and is 5 associated with obesity and metabolic disorders. This study sought to examine the relationship between percent of energy intake from ultra-processed foods (PEI-UPF) during pregnancy and maternal gestational weight gain, maternal lipids and glycemia, and neonatal body composition. We also compared the PEI-UPF indicator against the US government's Healthy Eating Index-2010 (HEI-2010).

9 Methods. Data were used from a longitudinal study performed in 2013-2014 at the Women's Health 10 Center and Obstetrics \& Gynecology Clinic in St. Louis, MO, USA. Subjects were pregnant women in the normal and obese weight ranges, as well as their newborns $(n=45)$. PEI-UPF and the Healthy Eating Index-2010 (HEI-2010) were calculated for each subject from a one-month food frequency questionnaire (FFQ). Multiple regression (ANCOVA-like) analysis was used to analyze the relationship between PEI-UPF or HEI-2010 and various clinical outcomes. The ability of these dietary indices to predict clinical outcomes was also compared with the predictive abilities of total energy intake and total fat intake.

Results. An average of $54.4 \pm 13.2 \%$ of energy intake was derived from UPFs. A 1\%-point increase in PEI-UPF was associated with a $1.33 \mathrm{~kg}$ increase in gestational weight gain $(\mathrm{p}=0.016)$. Similarly, a 1\%-point increase in PEI-UPF was associated with a $0.22 \mathrm{~mm}$ increase in thigh skinfold $(\mathrm{p}=0.045)$, $0.14 \mathrm{~mm}$ in subscapular skinfold $(\mathrm{p}=0.026)$, and 0.62 percentage points of total body adiposity $(\mathrm{p}=$ $0.037)$ in the neonate.

Discussion. PEI-UPF (percent of energy intake from ultra-processed foods) was associated with and may be a useful predictor of increased gestational weight gain and neonatal body fat. PEI-UPF was a better predictor of all tested outcomes than either total energy or fat intake, and a better predictor of the three infant body fat measures than HEI-2010. UPF consumption should be limited during pregnancy and diet quality should be maximized in order to improve maternal and neonatal health. 


\section{Introduction}

It has been well-documented that nutrition before and during pregnancy can have long lasting effects on maternal and neonatal health outcomes (Imhoff-Kunsch \& Martorell 2012). In particular, consumption of ample fruits, vegetables, whole grains, and lean meats, and limited consumption of caffeine, alcohol, and foods high in saturated fat during pregnancy has been recommended (2013; 2017). Evidence has emerged showing that consumption of foods high in sugar (Petherick et al. 2014), saturated fat (Park et al. 2013) and sodium during pregnancy can be particularly harmful to both the pregnant woman and their neonates (Tay et al. 2012). Many of these foods can be categorized as ultraprocessed foods (UPF), which are assemblages of food substances designed to create durable, accessible, convenient and palatable ready-to-eat or ready-to-heat food products (Monteiro et al. 2017). These products are often consumed as snacks instead of home-prepared dishes, are low in fiber, whole grains, and vitamins (Monteiro et al. 2017) and include artificial colors, flavors, and preservatives, which can be particularly harmful for pregnant women (Halldorsson et al. 2010).

Ultra-processed foods (UPFs) are merely one group in a four-category classification system (NOVA) that was developed to guide consumers towards a healthy diet using food-based, rather than nutrientbased, dietary guidelines (Monteiro et al. 2017). There is increasing evidence that high consumption of UPFs is indicative of poor diet and is associated with obesity, metabolic syndrome and cardiovascular disease in non-gravid adults (Canella et al. 2014; Costa Louzada et al. 2015; Louzada et al. 2015a; Louzada et al. 2015b; Martinez Steele et al. 2016; Moubarac et al. 2013). However, the relationship between the percent of energy intake from ultra-processed foods (PEI-UPF) during pregnancy and maternal and neonatal health outcomes has not been examined. Therefore, the purpose of this study was to determine the association between UPF consumption in pregnant US women and selected maternal/newborn health outcomes.

To do this, we used data collected by Tinius et al. on the health of 45 pregnant women and their neonates in St. Louis, MO, USA (Tinius et al. 2015; Tinius et al. 2016b). In the original study's design, only women within the normal or obese BMI ranges $\left(18.0-24.9 \mathrm{~kg} / \mathrm{m}^{2}\right.$ or $\left.30.0-45.0 \mathrm{~kg} / \mathrm{m}^{2}\right)$ were included. Overweight women (BMI of $25.0-29.9 \mathrm{~kg} / \mathrm{m}^{2}$ ) were excluded. It was found that the lean and obese groups only differed in gestational weight gain and maternal weight. No significant differences in PEI-UPF or other clinical outcomes were found between the two groups. However, the two groups were modeled as having different slopes (with respect to PEI-UPF) as well as intercepts to allow greater model flexibility. 
We hypothesize that the percent of energy intake coming from UPF could serve as a concise measure of the diet quality of this sample of pregnant US women. Further, we hypothesize that PEI-UPF could be an efficient predictor of maternal and neonatal health outcomes. These include maternal gestational weight gain (GWG) and neonatal anthropometrics. The ability of UPF consumption to predict these outcomes is clinically important as high GWG is generally associated with high postpartum weight retention (Gunderson \& Abrams 1999), and with the child having a higher BMI early in life (Lau et al. 2014; Mourtakos et al. 2016). More broadly, research has shown that maternal obesity can negatively influence neonatal outcomes in a variety of ways (Castro \& Avina 2002). These patterns almost certainly do not end at birth: Catalano et al. found that infant body fat percentage in particular (as opposed to body weight) can be a significant predictor of early childhood, and possibly adult, obesity (Catalano et al. 2003). Additionally, skinfold thickness measurements can be a predictor of insulin resistance and diabetes later in life (Yajnik et al. 2003).Therefore, the ability to determine the role of UPF consumption in maternal and neonatal health is important.

A secondary aim of the study was to compare the abilities of PEI-UPF and another dietary quality index, the Healthy Eating Index-2010 (HEI-2010), to predict maternal GWG and neonatal body composition. The HEI-2010 is a number ranging from 0 (worst) to 100 (best) that reflects the consumption of desirable macronutrients and food groups (fruits, vegetables, etc.), and avoidance of unhealthy foods (refined grains, sodium, and empty calories). The HEI-2010 measures diet quality according to the 2010 Dietary Guidelines for Americans (Guenther et al. 2014), and has been shown to have significant associations with biomarkers and clinical outcomes in gravid and non-gravid adults (Reedy et al. 2014; Shapiro et al. 2016). However, HEI-2010 has not been directly compared with PEIUPF in this regard. The HEI-2010 is often computed using 24-hour food recalls or FFQs such as the US National Institutes of Health's Diet History Questionnaire II (DHQ II) (2010), in which subjects reported their consumption of various unprocessed, prepared, and packaged foods over the past month. Tinius et al. administered the DHQ II to participants, and found that macronutrient intake was largely similar between lean and obese study groups, although active obese women tended to consume more fat than inactive obese women (Tinius et al. 2015; Tinius et al. 2016b). We note that the DHQ II can be used in a variety of other ways, such as measuring how many servings of a food were consumed (Yang \& Rose 2014), or calculating consumption of ultra-processed foods.

\section{Methods}

\section{Study Design}


90 This study used data collected by Tinius et al. as described above. Approval for this study was granted

91 by the Institutional Review Board at Washington University (IRB ID: 201306109). Written informed

92 consent was obtained from each participant. More information about how maternal and neonatal

93 outcomes were collected can be found elsewhere (Tinius et al. 2015; Tinius et al. 2016b).

94 In the original study, all women had viable singleton pregnancies and no evidence of fetal

95 abnormalities (both confirmed by ultrasound), and were recruited near the end of their second

96 trimester. The majority of maternal health markers were measured during two visits, both of which

97 occurred between 32 and 37 weeks gestation. Visit 1 occurred, on average, at 34 weeks, while Visit 2

98 occurred, on average, at 35 weeks. Maternal dietary indices were based on the 30 days preceding Visit

99 1, physical activity data were based on the week following Visit 1, and HDL (along with LDL) were

100 measured at Visit 2. Neonatal measurements were obtained after delivery and before discharge from

101 the hospital. In our study, key outcomes included maternal GWG and net triglyceride levels, as well as

102 neonatal percent body fat and site-specific skinfold measurements. Free fatty acids, fasting

103 insulin/glucose and C-reactive protein were measured in both mother and infant. These data were

104 obtained as part of previously published studies (Tinius et al. 2015; Tinius et al. 2016b).

\section{Survey Instrument}

106 As part of Visit 1, Tinius et al. administered the US National Institutes of Health's Diet History

107 Questionnaire II (DHQ II) (2010). For the present study, the DHQ II was primarily used to calculate

108 the percentage of energy intake that comes from ultra-processed foods (PEI-UPF). The HEI-2010, total

109 energy intake, and total fat intake were also calculated to compare their predictive abilities, in terms of

110 maternal and neonatal outcomes, with that of PEI-UPF. For each food on the DHQ II, the participant

111 was asked to choose one of eight options that best characterized the frequency of consumption, ranging

112 from "never" to " 2 or more times per day". For beverages, options ranged from "never" to "6 or more

113 times per day". Participants chose one of three options of typical serving sizes that best described the

114 amount consumed. The total amount consumed per month was determined by multiplying the average

115 of the frequency range with the average of the amount range. For condiments, participants chose one of

116 five options reflecting what fraction of the time it was added to the main food. Dietary supplements

117 were not considered.

118 The amount of each food consumed per month was converted to grams using a US Department of

119 Agriculture (USDA) database. Each food was classified, according to the NOVA classification scheme, 
120 as (1) an unprocessed or minimally processed food, (2) a processed culinary ingredient, (3) a processed 121 food, or (4) an ultra-processed food. Thirty-three subgroups (nested within the main groups) were used 122 to further classify the foods. The quantities of seven different nutrients obtained from each

123 group/subgroup were then calculated for each subject. Due to energy content inaccuracies in the USDA 124 database, the energy in $100 \mathrm{~g}$ of each food had to be recalculated as follows:

$$
\text { Energy }(\mathrm{MJ})=0.017 \frac{\mathrm{MJ}}{\text { gram }} \cdot(\text { Grams Carbohydrate }+ \text { Grams Protein })+0.037 \frac{\mathrm{MJ}}{\text { gram }} \cdot \text { Grams Fat }
$$

125 where MJ represents megajoules.

126 In general, when several different foods (such as jam, jelly, and honey) were combined in a single

127 question, nutrient information from the most commonly consumed food was used.

\section{Data Management}

129

130

Microsoft Excel 2013 was used for data entry, and spreadsheets were imported into R 3.2.3 (Team 2015) for calculations and statistical analysis. Several tables were automatically constructed using the stargazer package (Hlavac 2015) within R. Missing frequency or amount data for individual foods were estimated using random forest imputation, through the missForest package in R (Stekhoven 2013).

The HEI-2010 was computed using the Diet*Calc Analysis Program (2012) and the USDA's Food Patterns Equivalents Database. SAS version 9.4 (Institute 2012) (2002-2012, SAS Institute, Cary, NC, USA) was then used to run the National Cancer Institute's HEI-2010 scoring program.

\section{Statistical Analysis}

Simple matrix operations yielded the percentage of energy intake from ultra-processed foods (PEIUPF) for each study participant. This number was used as the primary measure of diet quality. Diagnostic tests (for normality, linearity, independence, and homoscedasticity) were carried out to determine the appropriateness of linear modelling. Then, an ANCOVA-like model was used to analyze the relationship between PEI-UPF and the various clinical outcome variables.

For the analysis of maternal health outcomes, age (continuous), race (Caucasian or African American/other), weight status (lean or obese), socioeconomic status (Primarily Low-Income Clinic or Primarily High-Income Clinic), average daily energy and fat intake (continuous), and percent of time spent in moderate physical activity (continuous) were controlled for (Table 1). In the neonatal outcome analyses, we controlled for maternal age, race, weight status, socioeconomic status, average daily 
147 energy and fat intake, percent of time spent in moderate physical activity, and gestational age at which 148 neonatal measurements were taken (continuous). All interactions with PEI-UPF were tested, and only 149 significant interaction terms were included in the final models. However, the PEI-UPF * Obese Weight

150 Status interaction was forced into all models, due to the special effect maternal obesity can have on 151 neonatal outcomes. Essentially, the lean and obese groups each had a separate slope coefficient $(\beta)$ for 152 the effect of UPF consumption on the clinical outcome.

153 Extra sum-of-squares F-tests and adjusted $\mathrm{R}^{2}$ values were used to compare the predictive ability of 154 PEI-UPF and HEI-2010. Unlike P-values, which measure association, Adjusted $\mathrm{R}^{2}$ measures the 155 predictive power of a model, while correcting for the number of regressors (models with many 156 extraneous regressors are penalized). Finally, since the assumption of normality was met, we used 157 Pearson correlation to determine the association between HEI-2010 and PEI-UPF. All tests were two158 sided, and $\mathrm{p}<0.05$ was considered significant.

\section{Results}

160 The present study is based upon previously published data with a sample size of $\mathrm{n}=50$. However, 161 records with missing FFQ or clinical outcome data had to be excluded from this study. Of the final sample $(n=45)$, sixteen women are from the lean study group $(n=16)$ while the remainder $(n=29)$ are

163 from the obese group. Detailed subject characteristics are presented in Table 1. The majority of women 164 visited a primarily high-income clinic (57.8\%), were nulliparous (55.6\%), and obese (64.4\%). Equal numbers of women were Caucasian and African American (46.7\% each), and the remaining 6.7\% were Hispanic or Asian. The average PEI-UPF was $54.4 \pm 13.2 \%$ and the average percentage of energy intake for both processed and ultra-processed foods together was 63.2\% (not shown in table). Among ultra-processed foods, the most consumed subgroup was Cakes, Cookies and Pies (5.8\% of total energy). Only two out of all thirty-three subgroups had higher average consumption - fruits $(9.1 \%$ of total energy intake) and grains (9.8\%) (not shown in table).

171 Further detail showing the quantity of nutrients obtained from each main food group is given in Table

172 2. As with energy intake, the participants' total carbohydrate, fat, sugar and sodium intakes were 173 primarily derived from ultra-processed foods $(57.0 \%, 58.8 \%, 57.9 \%$ and $65.7 \%$ of total dietary intake, 174 respectively). On the other hand, 39.9\% of fiber was obtained from Group 4 foods. Indeed, pregnant 175 women who limited their intake of ultra-processed foods tended to have better health outcomes for 176 themselves and their infants. Tables 3 and 4 present the detailed results of multiple regression analysis 
177 on newborn and maternal outcomes, respectively. The association between PEI-UPF and GWG was

178 observed only in the fully adjusted model, after controlling for maternal age, race, socioeconomic

179 status, weight status, average daily energy and fat intake, and time spent in moderate physical activity.

180 Likewise, the association of PEI-UPF with newborn body composition was observed only after

181 controlling for maternal age, race, socioeconomic status, weight, average daily energy and fat intake,

182 time spent by the woman in moderate physical activity, and gestational age at time of measurement.

183 However, in each of the four models, the mother's weight status (lean or obese) had no significant

184 slope or intercept effect on the relation between PEI-UPF and the clinical outcome. A number of

185 biomarkers including blood levels of triglycerides (data available for mother only), free fatty acids,

186 fasting glucose/insulin, and C-reactive protein had no significant association with PEI-UPF in either

187 mothers or infants.

188 Various interaction terms with PEI-UPF were tested, and only the interaction with age was found to be

189 significant ( $\mathrm{p} \leq 0.030$ for all four outcome variables). Thus, for older pregnant women, increased PEI-

190 UPF has less of an effect on poor health outcomes than for younger women, as indicated by the

191 negative coefficients for the interaction terms. All other interaction terms with PEI-UPF were not

192 significant.

193 The predictive ability of PEI-UPF was also compared with several other measures. In adjusted models

194 with only one dietary predictor (PEI-UPF, HEI-2010, total energy intake or total fat intake), PEI-UPF

195 was more strongly associated with all clinical outcomes than either total energy or fat intake (Table 5).

196 Indeed, PEI-UPF retained a significant relationship with GWG (p=0.016) (Table 3), as well as

197 neonatal thigh skinfold thickness $(p=0.045)$, subscapular skinfold thickness $(p=0.026)$ and body fat

198 percentage $(\mathrm{p}=0.037)$ (Table 4$)$, even after controlling for total energy and fat intake. This suggests

199 that PEI-UPF measures an aspect of diet that is independent of total energy and total fat intake.

200 Overall, PEI-UPF had a strong negative correlation with HEI-2010, with $\mathrm{r}=-0.74$ (95\% CI: -0.85 , -

201 0.56), indicating that both measures of diet quality are fairly consistent. Additionally, in models with

202 one dietary predictor, maternal HEI-2010 scores were strongly associated with HDL cholesterol $(\mathrm{p}=$ 203 0.0020) (not shown in table), GWG $(\mathrm{p}=0.0011)$, and neonatal subscapular skinfold thickness ( $\mathrm{p}=$ 204 0.026) (Table 5).

205 In fully adjusted models including total energy and fat intake, the HEI-2010 was a better predictor of 206 gestational weight gain than PEI-UPF (Adj. $\mathrm{R}^{2}=0.26$, as opposed to 0.14 for PEI-UPF). However, 
207 PEI-UPF was still a better predictor of infant body fat percentage, thigh skinfold thickness, and 208 subscapular skinfold thickness than the HEI-2010 (Adj. $\mathrm{R}^{2}=0.01,0.14$, and 0.10, as opposed to -0.09 , $209-0.02$, and -0.02 , respectively) (not shown in table). Although HEI-2010 has a greater association with 210 subscapular skinfold thickness than PEI-UPF (according to P-values in Table 5), Adjusted $\mathrm{R}^{2}$ values 211 indicate that overall the HEI-2010 model is a worse predictor than the PEI-UPF model. Furthermore, 212 adding HEI-2010 as a predictor in our four fully adjusted PEI-UPF models did not significantly 213 improve fit ( $\mathrm{p} \geq 0.097$ from extra sum-of-squares F-test in all cases). The failure of HEI-2010 to 214 improve model fit was likely caused by the strong (negative) correlation between PEI-UPF and HEI2152010.

\section{Discussion}

217 The results show a strong positive association of PEI-UPF with GWG and with neonatal 218 anthropometrics (i.e. subscapularis and thigh skinfold thicknesses and body fat percentage). This study 219 demonstrates that many pregnant women are obtaining the majority of their energy from ultra220 processed foods, and these ultra-processed foods may also be worsening health outcomes for 221 themselves and their children. These relationships are essentially the same in both lean and obese mothers. Indeed, the majority of participants' carbohydrate, fat, sugar, sodium, and energy were obtained from UPF, which is consistent with the refined ingredients and highly palatable nature of such foods. As such, it is not surprising that UPF consumption negatively affects health.

The identification of causes of excessive gestational weight gain is clinically important as excessive gestational weight gain can have serious consequences for the postpartum women and their neonates. It leads to excessive postpartum weight retention (Gunderson \& Abrams 1999), which in turn can contribute to long-term obesity and associated comorbidities including type 2 diabetes, cardiovascular disease, mental health issues, and cancer (2009). For the neonate, excess adiposity is likely to continue into childhood (Mei et al. 2003), and childhood obesity is a strong predictor of adult obesity (Freedman et al. 2005). Thus, higher body fat as an infant may contribute to long-term risk for obesity and its associated comorbidities (Catalano \& Ehrenberg 2006; Tinius et al. 2016a). Because UPF consumption was related not only to excessive gestational weight gain, but also neonatal adiposity, maternal diet quality modification could substantially improve long-term health outcomes for mother and child. Interestingly, a number of successful interventions to limit excessive GWG emphasize energy or fat restriction, or other macronutrient targets (Gardner et al. 2011; Phelan et al. 2011). Despite the 
237 popularity of energy- and fat-restricting diets, GWG was more strongly associated with PEI-UPF than 238 total energy or fat intake ( $p=0.017$ for PEI-UPF compared to $p=0.73$ and $p=0.88$ for total energy 239 and fat intake). More generally, although low fat ultra-processed foods are ubiquitous, such results cast 240 doubt on the health benefits of these low fat foods. We believe interventions to limit GWG could be 241 even more successful if they also emphasized a minimally-processed diet, since our results show that 242 PEI-UPF captures information about diet quality, which total fat or energy intake cannot. In general, 243 our results suggest that consumption of UPF may be a key factor contributing to unfavorable maternal 244 and neonatal outcomes. This study showed that poor diet quality during pregnancy increases neonatal adiposity independent of maternal weight and maternal moderate physical activity; thus, maternal diet quality is an important direction of future study. Specifically, diet quality seems to be more important than the amount of energy consumed. Thus, from a clinical standpoint, pregnant women should be educated to focus less on the total energy consumed, and more on the source of that energy. Interestingly, the nutrient profiles indicate that processed foods generally have less fiber and more sodium than UPF. Thus, while small amounts of processed foods are part of any diet and acceptable in moderation, clear preference should be given to unprocessed/minimally processed foods. It is also important to highlight the need for moderation when using salt, sugar and oil in home based meal preparations.

Furthermore, almost all currently used tools for assessing diet are largely quantity based instead of quality based, which is one of the main reasons for measuring UPF consumption. Because many currently used tools assess quantity, we also wanted to assess the ability of the HEI-2010 to predict maternal and neonatal outcomes. As part of our secondary aim, our results did show that a quantityfocused measure such as HEI-2010 can be a useful predictor of gestational weight gain. Despite the high correlation between PEI-UPF and HEI-2010, PEI-UPF is a better predictor of neonatal body fat percentage and skinfold thickness at the thigh and subscapularis. This comparison is based on Adjusted $\mathrm{R}^{2}$ values $(0.01,0.14$, and 0.10 for PEI-UPF, as opposed to $-0.09,-0.02$, and -0.02 for HEI-2010). Interestingly, Shapiro et al. found that a low maternal HEI-2010 score was associated with higher neonatal body fat percentage, in a sample size of $>1,000$ woman and infant pairs (Shapiro et al. 2016). We were unable to confirm this finding (in our study, $p=0.30$ for association with body fat percentage). The differences in predictive ability between HEI-2010 and PEI-UPF indicate that each statistic measures different aspects of the diet, and therefore both are useful. To achieve the optimal diet, one must both limit intake of UPFs as well as eat a variety of different nutrients. 
268 This study has several notable strengths, including being the first effort to measure UPF consumption 269 in pregnant women, and to correlate PEI-UPF with maternal and neonatal clinical outcomes.

270 Additionally, it is only the second study to examine PEI-UPF in the United States, where the percent of 271 the diet coming from UPFs is much higher than in some other countries (Canella et al. 2014; Martinez 272 Steele et al. 2016; Monteiro et al. 2013). However, this study presents some limitations. Due to the 273 design of the original longitudinal study, only women within the normal or obese weight ranges were 274 included (BMI between $18.0 \mathrm{~kg} / \mathrm{m}^{2}$ and $24.9 \mathrm{~kg} / \mathrm{m}^{2}$ or between $30.0 \mathrm{~kg} / \mathrm{m}^{2}$ or $45.0 \mathrm{~kg} / \mathrm{m}^{2}$ ). Thus, 275 women in the overweight range were excluded, and the study results may not be applicable to such 276 women. Additionally, the racial composition, with essentially equal numbers of Caucasians and 277 African Americans, and very few other minorities, is not representative of the entire US population. 278 The design of the survey instrument presents further limitations. Since food frequency and portion 279 sizes were collected in a semi-quantitative/categorical format, often with as few as three options, there 280 was some error simply because respondents had to round off quantities. Additionally, somewhat 281 subjective researcher input was required to categorize each DHQ II food according to the NOVA 282 scheme. For example, homemade bread would be a processed food, but for this study, bread was 283 classified as ultra-processed since most bread consumed in the US meets this definition. A full listing 284 of classifications (along with justification) can be found in the Appendix.

285 A greater error we could not eliminate is the fact that participants may underreport their food intake. 286 Previous research found that postmenopausal women underestimated their energy intake by $21 \%$ on a 287 FFQ (Horner et al. 2002). However, another study found that food frequency questionnaires (FFQs) 288 inquiring about consumption over a several-month period provide reproducible and valid measures of 289 relative dietary intakes in pregnant populations (Vioque et al. 2013). However, since we are using 290 percentages of energy intake as the main predictor rather than absolute energy, we feel our data may 291 not be subject to the same degree of error. Finally, another major limitation is that administering the 292 DHQ II once, at Visit 1, effectively only assesses maternal diet at 30-34 weeks gestation. It is unlikely 293 that this assessed diet accurately represents diet across the entire pregnancy, since previous research 294 indicates that intake of certain foods and overall caloric intake vary across the three trimesters (Durnin 295 1991; Rifas-Shiman et al. 2006).

\section{Conclusions}

This study showed that consumption of ultra-processed foods leads to unfavorable pregnancy outcomes including excessive maternal gestational weight gain and increased neonatal body fatness. For both 
299 mother and neonate, excess adiposity is likely to remain, contributing to associated comorbidities such 300 as Type II diabetes, cardiovascular disease, mental health issues, cancer. Reducing dietary consumption 301 of ultra-processed foods may be a potential avenue for improving short and long term maternal and 302 neonatal health, making this an important direction for future research. A natural, minimally-processed 303 diet centered on home cooking should be promoted among pregnant women.

\section{Acknowledgments}

305 We are grateful to Carlos A. Monteiro from University of Sao Paulo for his valuable input regarding 306 the NOVA classification system and analyses. We are also grateful to Mary Brugge and Nicholas 307 Schroeder, DPT (Doctorate in Physical Therapy) students at Washington University in St. Louis, for 308 their help with preparation of the data for analysis. We wish to thank Ken Bishop for his assistance 309 with quality control in our DHQ II data file. Special thanks to the study participants and their 310 newborns. 


\section{References}

313 2009. In: Rasmussen KM, and Yaktine AL, eds. Weight Gain During Pregnancy: Reexamining the 314 Guidelines. Washington (DC).

315 2010. Diet History Questionnaire. 2.0 ed. Rockville, MD, USA: National Cancer Institute, 316 Epidemiology and Genomics Research Program.

317 2012. Diet*Calc Analysis Program. 1.5.0 ed. Rockville, MD, USA: National Cancer Institute, 318 Epidemiology and Genomics Research Program.

319 2013. Healthy eating during your pregnancy. Available at https://www.eatforhealth.gov.au/sites/default/files/files/the guidelines/n55h healthy eating du ring_pregnancy.pdf.

2017. Foods to avoid in pregnancy. Available at http://www.nhs.uk/Conditions/pregnancy-andbaby/pages/foods-to-avoid-pregnant.aspx.

324 Canella DS, Levy RB, Martins AP, Claro RM, Moubarac JC, Baraldi LG, Cannon G, and Monteiro CA. 2014. Ultra-processed food products and obesity in Brazilian households (2008-2009). PLoS One 9:e92752. 10.1371/journal.pone.0092752

Catalano PM, and Ehrenberg HM. 2006. The short- and long-term implications of maternal obesity on the mother and her offspring. Bjog 113:1126-1133. 10.1111/j.1471-0528.2006.00989.x

Catalano PM, Thomas A, Huston-Presley L, and Amini SB. 2003. Increased fetal adiposity: a very sensitive marker of abnormal in utero development. American journal of obstetrics and gynecology 189:1698-1704.

Costa Louzada ML, Martins AP, Canella DS, Baraldi LG, Levy RB, Claro RM, Moubarac JC, Cannon G, and Monteiro CA. 2015. Ultra-processed foods and the nutritional dietary profile in Brazil. Rev Saude Publica 49:38. 10.1590/s0034-8910.2015049006132

Durnin JV. 1991. Energy requirements of pregnancy. Diabetes 40:152-156.

Freedman DS, Khan LK, Serdula MK, Dietz WH, Srinivasan R, Berenson GS, Khan K, and Serdula K. 2005. The relation of childhood BMI to adult adiposity: the Bogalusa Heart Study. Pediatrics 115:22-27.

Gardner B, Wardle J, Poston L, and Croker H. 2011. Changing diet and physical activity to reduce gestational weight gain: a meta-analysis. Obesity reviews 12:e602-e620. 
343 Guenther PM, Kirkpatrick SI, Reedy J, Krebs-Smith SM, Buckman DW, Dodd KW, Casavale KO, and

Carroll RJ. 2014. The Healthy Eating Index-2010 is a valid and reliable measure of diet quality according to the 2010 Dietary Guidelines for Americans. J Nutr:jn. 113.183079.

Gunderson EP, and Abrams B. 1999. Epidemiology of gestational weight gain and body weight changes after pregnancy. Epidemiologic reviews 21:261-275.

Halldorsson TI, Strom M, Petersen SB, and Olsen SF. 2010. Intake of artificially sweetened soft drinks and risk of preterm delivery: a prospective cohort study in 59,334 Danish pregnant women. $\mathrm{Am}$ J Clin Nutr 92:626-633. 10.3945/ajcn.2009.28968

Hlavac M. 2015. stargazer: Well-Formatted Regression and Summary Statistics Tables. R package version 5.2. .

Horner NK, Patterson RE, Neuhouser ML, Lampe JW, Beresford SA, and Prentice RL. 2002. Participant characteristics associated with errors in self-reported energy intake from the Women's Health Initiative food-frequency questionnaire. Am J Clin Nutr 76:766-773.

Imhoff-Kunsch B, and Martorell R. 2012. Nutrition interventions during pregnancy and maternal, newborn and child health outcomes. Paediatr Perinat Epidemiol 26 Suppl 1:1-3. $10.1111 / \mathrm{j} .1365-3016.2012 .01271 . x$

Institute S. 2012. SAS. 9.4 ed. Cary, NC, USA: SAS Institute.

Lau EY, Liu J, Archer E, McDonald SM, and Liu J. 2014. Maternal weight gain in pregnancy and risk of obesity among offspring: a systematic review. Journal of obesity 2014.

Louzada ML, Baraldi LG, Steele EM, Martins AP, Canella DS, Moubarac JC, Levy RB, Cannon G, Afshin A, Imamura F, Mozaffarian D, and Monteiro CA. 2015a. Consumption of ultraprocessed foods and obesity in Brazilian adolescents and adults. Prev Med 81:9-15. 10.1016/j.ypmed.2015.07.018

Louzada ML, Martins AP, Canella DS, Baraldi LG, Levy RB, Claro RM, Moubarac JC, Cannon G, and Monteiro CA. 2015b. Impact of ultra-processed foods on micronutrient content in the Brazilian diet. Rev Saude Publica 49:45. 10.1590/S0034-8910.2015049006211

Martinez Steele E, Baraldi LG, Louzada ML, Moubarac JC, Mozaffarian D, and Monteiro CA. 2016. Ultra-processed foods and added sugars in the US diet: evidence from a nationally representative cross-sectional study. BMJ Open 6:e009892. 10.1136/bmjopen-2015-009892

Mei Z, Grummer-Strawn LM, and Scanlon KS. 2003. Does overweight in infancy persist through the preschool years? An analysis of CDC Pediatric Nutrition Surveillance System data. Soz Praventivmed 48:161-167. 
375 Monteiro CA, Cannon G, Moubarac J-C, Levy RB, Louzada MLC, and Jaime PC. 2017. The UN 376 Decade of Nutrition, the NOVA food classification and the trouble with ultra-processing. 377 Public Health Nutr:1-13.

378 Monteiro CA, Moubarac JC, Cannon G, Ng SW, and Popkin B. 2013. Ultra-processed products are 379 becoming dominant in the global food system. Obesity reviews 14:21-28.

Moubarac JC, Martins AP, Claro RM, Levy RB, Cannon G, and Monteiro CA. 2013. Consumption of 381 ultra-processed foods and likely impact on human health. Evidence from Canada. Public Health Nutr 16:2240-2248. 10.1017/S1368980012005009

Mourtakos S, Tambalis K, Panagiotakos D, Antonogeorgos G, Alexi C, Georgoulis M, Saade G, and Sidossis L. 2016. Association between gestational weight gain and risk of obesity in preadolescence: a longitudinal study (1997-2007) of 5125 children in Greece. Journal of Human Nutrition and Dietetics.

Park S, Kim MY, Baik SH, Woo JT, Kwon YJ, Daily JW, Park YM, Yang JH, and Kim SH. 2013. Gestational diabetes is associated with high energy and saturated fat intakes and with low plasma visfatin and adiponectin levels independent of prepregnancy BMI. Eur J Clin Nutr 67:196-201. 10.1038/ejcn.2012.207

Petherick ES, Goran MI, and Wright J. 2014. Relationship between artificially sweetened and sugarsweetened cola beverage consumption during pregnancy and preterm delivery in a multi-ethnic cohort: analysis of the Born in Bradford cohort study. Eur J Clin Nutr 68:404-407. 10.1038/ejcn.2013.267

Phelan S, Jankovitz K, Hagobian T, and Abrams B. 2011. Reducing excessive gestational weight gain: lessons from the weight control literature and avenues for future research. Womens Health (Lond) 7:641-661. 10.2217/whe.11.70

Reedy J, Krebs-Smith SM, Miller PE, Liese AD, Kahle LL, Park Y, and Subar AF. 2014. Higher diet quality is associated with decreased risk of all-cause, cardiovascular disease, and cancer mortality among older adults. $J$ Nutr 144:881-889.

Rifas-Shiman SL, Rich-Edwards JW, Willett WC, Kleinman KP, Oken E, and Gillman MW. 2006. Changes in dietary intake from the first to the second trimester of pregnancy. Paediatr Perinat Epidemiol 20:35-42. 10.1111/j.1365-3016.2006.00691.x

Shapiro AL, Kaar JL, Crume TL, Starling AP, Siega-Riz AM, Ringham BM, Glueck DH, Norris JM, Barbour LA, Friedman JE, and Dabelea D. 2016. Maternal diet quality in pregnancy and 
406

407

408

409

410

411

412

413

414

415

416

417

418

419

420

421

422

423

424

425

426

427

428

429

430

431

432

433

434

435

neonatal adiposity: the Healthy Start Study. Int J Obes (Lond) 40:1056-1062.

10.1038/ijo.2016.79

Stekhoven DJ. 2013. missForest: Nonparametric Missing Value Imputation using Random Forest. 1.4 ed: The Comprehensive R Archive Network.

Tay S, Blache D, Gregg K, and Revell D. 2012. Consumption of a high-salt diet by ewes during pregnancy alters nephrogenesis in 5-month-old offspring. Animal 6:1803-1810. $10.1017 / \mathrm{S} 1751731112000584$

Team RC. 2015. R: A language and environment for statistical computing. Vienna, Austria: R Foundation for Statistical Computing.

Tinius RA, Cahill AG, and Cade WT. 2016a. Origins in the Womb: Potential Role of the Physical Therapist in Modulating the Deleterious Effects of Obesity on Maternal and Offspring Health Through Movement Promotion and Prescription During Pregnancy. Phys Ther. $10.2522 / \mathrm{ptj} .20150678$

Tinius RA, Cahill AG, Strand EA, and Cade WT. 2015. Altered maternal lipid metabolism is associated with higher inflammation in obese women during late pregnancy. Integr Obes Diabetes 2:168-175.

Tinius RA, Cahill AG, Strand EA, and Cade WT. 2016b. Maternal inflammation during late pregnancy is lower in physically active compared with inactive obese women. Appl Physiol Nutr Metab 41:191-198. 10.1139/apnm-2015-0316

Vioque J, Navarrete-Munoz EM, Gimenez-Monzo D, Garcia-de-la-Hera M, Granado F, Young IS, Ramon R, Ballester F, Murcia M, Rebagliato M, and Iniguez C. 2013. Reproducibility and validity of a food frequency questionnaire among pregnant women in a Mediterranean area. Nutr $J$ 12:26. 10.1186/1475-2891-12-26

Yajnik CS, Fall CH, Coyaji KJ, Hirve SS, Rao S, Barker DJ, Joglekar C, and Kellingray S. 2003. Neonatal anthropometry: the thin-fat Indian baby. The Pune Maternal Nutrition Study. Int J Obes Relat Metab Disord 27:173-180. 10.1038/sj.ijo.802219

Yang J, and Rose DJ. 2014. Long-term dietary pattern of fecal donor correlates with butyrate production and markers of protein fermentation during in vitro fecal fermentation. Nutr Res 34:749-759. 10.1016/j.nutres.2014.08.006 


\section{Table $\mathbf{1}$ (on next page)}

Demographic and lifestyle characteristics of analyzed respondents, $n=45$.

Table 1 gives the frequencies for each level of relevant categorical variables, as well as mean and standard deviation for continuous variables. 
1 Table 1 gives the frequencies for each level of relevant categorical variables, as well as mean and 2 standard deviation for continuous variables.

\begin{tabular}{|c|c|}
\hline Maternal Characteristics & Percentage \\
\hline $\begin{array}{l}\text { Race } \\
\text { Caucasian } \\
\text { African-American } \\
\text { Other } \\
\end{array}$ & $\begin{array}{c}46.7 \% \\
46.7 \% \\
6.7 \% \\
\end{array}$ \\
\hline $\begin{array}{l}\text { Clinic Visited } \\
\text { Primarily Low-Income } \\
\text { Primarily High-Income }\end{array}$ & $\begin{array}{l}42.2 \% \\
57.8 \%\end{array}$ \\
\hline $\begin{array}{l}\text { Parity } \\
\text { Nulliparous } \\
\text { Multiparous }\end{array}$ & $\begin{array}{l}55.6 \% \\
44.4 \%\end{array}$ \\
\hline $\begin{array}{l}\text { Weight Status at beginning of study (i.e., before } 32 \text { weeks } \\
\text { gestation) } \\
\text { Lean } \\
\text { Obese }\end{array}$ & $\begin{array}{l}35.6 \% \\
64.4 \%\end{array}$ \\
\hline $\begin{array}{c}\text { Maternal Characteristics } \\
\text { (mostly at 32-37 weeks gestation) }\end{array}$ & Mean \pm SD \\
\hline PEI-UPF (\%) in the month preceding Visit 1 & $54.4 \pm 13.2$ \\
\hline HEI-2010 (0-100) based on the month preceding Visit 1 & $62.2 \pm 13.0$ \\
\hline Age (years) at Visit 1 & $27.2 \pm 5.1$ \\
\hline Gestational Age at Visit 1 (weeks) & $33.6 \pm 1.4$ \\
\hline Gestational Age at Visit 2 (weeks) & $34.7 \pm 1.3$ \\
\hline Pre-Pregnancy BMI at initiation of prenatal care & $30.1 \pm 7.3$ \\
\hline Body Fat (\%) at Visit 1 & $31.8 \pm 8.5$ \\
\hline $\begin{array}{l}\text { Gestational Weight Gain }(\mathrm{kg}) \text { between beginning of study and } \\
\text { admission for labor/delivery }\end{array}$ & $12.0 \pm 7.2$ \\
\hline HDL $(\mathrm{mg} / \mathrm{dL})$ at Visit 2 & $67.6 \pm 15.3$ \\
\hline LDL (mg/dL) at Visit 2 & $121.4 \pm 36.7$ \\
\hline $\begin{array}{l}\text { Time Spent in Moderate Physical Activity (\%) in the week } \\
\text { following Visit } 1\end{array}$ & $13.8 \pm 4.1$ \\
\hline Newborn Characteristics (within 48 hours of delivery) & Mean \pm SD \\
\hline Gestational Age when Neonatal Measurements Taken & $39.6 \pm 1.2$ \\
\hline Thigh Skinfold Thickness (mm) & $6.6 \pm 1.4$ \\
\hline Subscapular Skinfold Thickness $(\mathrm{mm})$ & $4.4 \pm 0.8$ \\
\hline Body Fat (\%) & $11.5 \pm 3.5$ \\
\hline
\end{tabular}




\section{Table 2 (on next page)}

Average nutrient intake by food group, $n=45$.

Table 2 shows that a majority of energy intake (54.4\%, on average) was obtained from ultraprocessed foods, but at the same time processed foods represent a significant source of fat and sodium, and cannot be disregarded. 
1 Table 2 shows that a majority of energy intake (54.4\%, on average) was obtained from ultra-

2 processed foods, but at the same time processed foods represent a significant source of fat and

3 sodium, and cannot be disregarded.

Table 2. Average nutrient intake by food group, $n=45$.

\begin{tabular}{|c|c|c|c|c|c|c|c|}
\hline & \multicolumn{7}{|c|}{ Mean Intake } \\
\hline Food Groups & $\begin{array}{l}\text { Absolute } \\
\text { (MJ/day) }\end{array}$ & $\begin{array}{l}\text { Carbohydrate } \\
\text { (\% of total } \\
\text { intake) }\end{array}$ & $\begin{array}{c}\text { Protein (\% of } \\
\text { total intake) }\end{array}$ & $\begin{array}{l}\text { Fat (\% of } \\
\text { total intake) }\end{array}$ & $\begin{array}{c}\text { Total Sugars } \\
\text { (\% of total } \\
\text { intake) }\end{array}$ & $\begin{array}{l}\text { Fiber (\% of } \\
\text { total intake) }\end{array}$ & $\begin{array}{l}\text { Sodium }(\% \\
\text { of total } \\
\text { intake) }\end{array}$ \\
\hline $\begin{array}{l}\text { 1. Unprocessed } \\
\text { or minimally } \\
\text { processed foods }\end{array}$ & 3.7 & 39.7 & 40.8 & 27.3 & 37.5 & 56.4 & 16.0 \\
\hline $\begin{array}{l}\text { 2. Processed } \\
\text { culinary } \\
\text { ingredients }\end{array}$ & 0.2 & 0.9 & 0.1 & 3.6 & 1.3 & 0 & 0.8 \\
\hline $\begin{array}{l}\text { 3. Processed } \\
\text { foods }\end{array}$ & 0.8 & 2.4 & 22.6 & 10.3 & 3.3 & 3.7 & 17.6 \\
\hline $\begin{array}{l}\text { 4. Ultra- } \\
\text { processed foods }\end{array}$ & 5.8 & 57.0 & 36.5 & 58.8 & 57.9 & 39.9 & 65.7 \\
\hline TOTAL & 10.5 & 100 & 100 & 100 & 100 & 100 & 100 \\
\hline
\end{tabular}


Table 3 (on next page)

Associations between PEI-UPF and Gestational Weight Gain, adjusted for maternal characteristics, $n=45$.

According to Table 3, PEI-UPF as well as the interaction between PEI-UPF and Age are significantly associated with GWG. 
1 According to Table 3, PEI-UPF as well as the interaction between PEI-UPF and Age are 2 significantly associated with GWG.

\begin{tabular}{|c|c|c|c|}
\hline \multirow[b]{2}{*}{ Subject Characteristic } & \multicolumn{3}{|c|}{ Gestational Weight Gain (kg) } \\
\hline & $\boldsymbol{\beta}$ & $95 \% \mathrm{CI}$ & P-value \\
\hline PEI-UPF (\%) in the month preceding Visit 1 & 1.3 & $(0.3,2.4)$ & 0.016 \\
\hline Age (years) at Visit 1 & 2.6 & $(0.6,4.6)$ & 0.014 \\
\hline PEI-UPF * Age & -0.05 & $(-0.09,-0.01)$ & 0.012 \\
\hline \multicolumn{4}{|l|}{ Maternal Weight Status (ref: Lean) } \\
\hline Obese & -5.1 & $(-25.1,15.0)$ & 0.61 \\
\hline PEI-UPF * Obese & 0.06 & $(-0.3,0.4)$ & 0.72 \\
\hline Avg. Daily Energy Intake (kcal) & 0.003 & $(-0.002,0.008)$ & 0.20 \\
\hline Avg. Daily Fat Intake (g) & -0.06 & $(-0.2,0.07)$ & 0.38 \\
\hline \multicolumn{4}{|l|}{ Race (ref: Caucasian) } \\
\hline African-American/Other & -7.9 & $(-13.7,-2.2)$ & 0.0085 \\
\hline \multicolumn{4}{|l|}{ Clinic Visited (ref: Primarily Low-Income) } \\
\hline Primarily High-Income & -2.0 & $(-7.6,3.6)$ & 0.47 \\
\hline $\begin{array}{l}\text { Time Spent in Moderate Physical Activity (\%) } \\
\text { in the week following Visit } 1\end{array}$ & -0.2 & $(-0.8,0.5)$ & 0.58 \\
\hline $\begin{array}{l}\text { Note: Gestational weight gain was measured fro } \\
\text { labor/delivery. } \\
\text { Note: Text in italics represents P-value }<0.05 \text {. }\end{array}$ & & & \\
\hline
\end{tabular}


Table 4 (on next page)

Associations between PEI-UPF and neonatal outcomes, adjusted for maternal characteristics, $n=45$.

Table 4 shows that PEI-UPF as well as the interaction between PEI-UPF and Age are significantly associated with thigh skinfold thickness, subscapular skinfold thickness, and body fat percentage in the newborn. 
1 Table 4 shows that PEI-UPF as well as the interaction between PEI-UPF and Age are

2 significantly associated with thigh skinfold thickness, subscapular skinfold thickness, and body

3 fat percentage in the newborn.

4

Table 4. Associations between PEI-UPF and neonatal outcomes, adjusted for maternal characteristics, $n=45$.

\begin{tabular}{|c|c|c|c|c|c|c|c|c|c|}
\hline \multirow[b]{3}{*}{ Subject Characteristic } & \multicolumn{9}{|c|}{ NEWBORN OUTCOME (measured within 48 hours of delivery) } \\
\hline & \multicolumn{3}{|c|}{$\begin{array}{c}\text { Thigh Skinfold Thickness } \\
\text { (mm) }\end{array}$} & \multicolumn{3}{|c|}{$\begin{array}{c}\text { Subscap. Skinfold Thickness } \\
(\mathrm{mm})\end{array}$} & \multicolumn{3}{|c|}{ Body Fat (\%) } \\
\hline & $\boldsymbol{\beta}$ & $95 \% \mathrm{CI}$ & $\begin{array}{c}\text { P- } \\
\text { value }\end{array}$ & $\boldsymbol{\beta}$ & $95 \% \mathrm{CI}$ & $\begin{array}{c}\text { P- } \\
\text { value }\end{array}$ & $\boldsymbol{\beta}$ & $95 \% \mathrm{CI}$ & P-value \\
\hline $\begin{array}{l}\text { PEI-UPF (\%) in the month } \\
\text { preceding Visit } 1\end{array}$ & 0.2 & $\begin{array}{c}(0.005, \\
0.4)\end{array}$ & 0.045 & 0.1 & $\begin{array}{c}(0.02, \\
0.3)\end{array}$ & 0.026 & 0.6 & $\begin{array}{c}(0.04, \\
1.2)\end{array}$ & 0.037 \\
\hline Age (years) at Visit 1 & 0.4 & $\begin{array}{c}(0.03 \\
0.8)\end{array}$ & 0.035 & 0.3 & $\begin{array}{c}(0.06 \\
0.5)\end{array}$ & 0.015 & 1.3 & $(0.2,2.4)$ & 0.023 \\
\hline PEI-UPF * Age & -0.008 & $\begin{array}{c}(-0.02 \\
-0.0008)\end{array}$ & 0.030 & -0.006 & $\begin{array}{l}(-0.01 \\
-0.001)\end{array}$ & 0.014 & -0.02 & $\begin{array}{l}(-0.05 \\
-0.004)\end{array}$ & 0.020 \\
\hline $\begin{array}{l}\text { Maternal Weight Status } \\
\text { (ref: Lean) - Obese }\end{array}$ & -2.6 & $\begin{array}{c}(-6.6 \\
1.4)\end{array}$ & 0.19 & -0.8 & $\begin{array}{c}(-3.1 \\
1.4)\end{array}$ & 0.46 & -3.0 & $\begin{array}{c}(-13.7 \\
7.7)\end{array}$ & 0.58 \\
\hline PEI-UPF * Obese & 0.06 & $\begin{array}{c}(-0.01 \\
0.1)\end{array}$ & 0.098 & 0.02 & $\begin{array}{c}(-0.02, \\
0.06)\end{array}$ & 0.35 & 0.09 & $\begin{array}{c}(-0.1, \\
0.3)\end{array}$ & 0.35 \\
\hline $\begin{array}{l}\text { Maternal Avg. Daily } \\
\text { Energy Intake (kcal) }\end{array}$ & -0.0009 & $\begin{array}{l}(-0.002 \\
0.0001)\end{array}$ & 0.081 & 0.0002 & $\begin{array}{c}(-0.0004, \\
0.0007)\end{array}$ & 0.55 & 0.0009 & $\begin{array}{c}(-0.002 \\
0.004)\end{array}$ & 0.48 \\
\hline $\begin{array}{l}\text { Maternal Avg. Daily Fat } \\
\text { Intake }(\mathrm{g})\end{array}$ & 0.03 & $\begin{array}{c}(0.003, \\
0.06)\end{array}$ & 0.030 & -0.0008 & $\begin{array}{c}(-0.02 \\
0.01)\end{array}$ & 0.91 & -0.01 & $\begin{array}{c}(-0.08, \\
0.06)\end{array}$ & 0.70 \\
\hline $\begin{array}{l}\text { Race (ref: Caucasian) - } \\
\text { African-American/Other }\end{array}$ & -0.3 & $\begin{array}{c}(-1.4, \\
0.9)\end{array}$ & 0.62 & -0.2 & $\begin{array}{c}(-0.8, \\
0.5)\end{array}$ & 0.63 & 0.3 & $\begin{array}{c}(-2.7, \\
3.4)\end{array}$ & 0.83 \\
\hline $\begin{array}{l}\text { Clinic Visited (ref: } \\
\text { Primarily Low-Income) - } \\
\text { Primarily High-Income }\end{array}$ & 0.3 & $\begin{array}{c}(-0.8, \\
1.5)\end{array}$ & 0.57 & -0.08 & $\begin{array}{c}(-0.7 \\
0.6)\end{array}$ & 0.81 & 1.4 & $\begin{array}{c}(-1.7 \\
4.6)\end{array}$ & 0.36 \\
\hline $\begin{array}{l}\text { Gestational Age when } \\
\text { Neonatal Measurements } \\
\text { Taken (weeks) }\end{array}$ & 0.3 & $\begin{array}{c}(-0.05 \\
0.7)\end{array}$ & 0.082 & 0.2 & $\begin{array}{c}(0.01 \\
0.5)\end{array}$ & 0.041 & -0.1 & $\begin{array}{c}(-1.2 \\
1.0)\end{array}$ & 0.83 \\
\hline $\begin{array}{l}\text { Time Spent in Moderate } \\
\text { Physical Activity }(\%) \text { in } \\
\text { the week following Visit } 1\end{array}$ & -0.05 & $\begin{array}{l}(-0.2 \\
0.08)\end{array}$ & 0.45 & -0.004 & $\begin{array}{c}(-0.08, \\
0.07)\end{array}$ & 0.91 & 0.04 & $\begin{array}{c}(-0.3 \\
0.4)\end{array}$ & 0.83 \\
\hline
\end{tabular}




\section{Table 5 (on next page)}

P-values for various dietary indices in models with only one dietary index.

Table 5 shows that for most of the clinical outcomes, PEI-UPF is a significant predictor even in the absence of other dietary predictors. HEI-2010 is sometimes a significant predictor, but Total Energy Intake and Total Fat Intake are not significant for any of the outcomes tested. 
1 Table 5 shows that for most of the clinical outcomes, PEI-UPF is a significant predictor even in 2 the absence of other dietary predictors. HEI-2010 is sometimes a significant predictor, but Total 3 Energy Intake and Total Fat Intake are not significant for any of the outcomes tested.

4

Table 5. P-values for various dietary indices in models with only one dietary index.

\begin{tabular}{lcccc}
\hline & \multicolumn{4}{c}{ Maternal or Newborn Outcome } \\
\hline Dietary Index & $\begin{array}{c}\text { Gestational Weight } \\
\text { Gain (kg) }\end{array}$ & $\begin{array}{c}\text { Thigh Skinfold } \\
\text { Thickness (mm) }\end{array}$ & $\begin{array}{c}\text { Subscap. Skinfold } \\
\text { Thickness (mm) }\end{array}$ & Body Fat (\%) \\
\hline PEI-UPF & 0.017 & 0.12 & 0.036 & 0.035 \\
HEI-2010 & 0.0011 & 0.41 & 0.026 & 0.30 \\
Total Energy Intake & 0.73 & 0.45 & 0.80 & 0.97 \\
Total Fat Intake & 0.88 & 0.59 & 0.75 & 0.76 \\
\hline
\end{tabular}

Note: All models were adjusted for age (continuous), race (Caucasian or African American/other), weight status (lean or obese), socioeconomic status (Primarily Low-Income Clinic or Primarily High-Income Clinic), and percent of time spent in moderate physical activity (continuous). Models for newborn outcomes were also adjusted for gestational age at which neonatal measurements were taken (continuous).

Note: Text in italics represents P-value $<0.05$. 